DOI:

\title{
Blokzincir Teknolojisinin Muhasebede Kullanımıyla İlgili Algıların Belirlenmesine Yönelik Bir Ölçek Geliştirme Çalışması*
}

\author{
Mehmet GÜNER**
}

\section{ÖZET}

Bu çalışma, blok zincir teknolojisinin muhasebe süreçlerinde kullanılabilirliği ile ilgili algıların tespit edilmesi ve söz konusu alglların belirlenmesi için bir ölçek geliştirilmesini amaçlamaktadır. Güvenlik, gizlilik, denetim, müşteri memnuniyeti ve mevzuat gereklilikleri muhasebe iş ve işlemlerinde son derece önemli kavramlardır. Söz konusu kavramların, blokzincir teknolojisinin kullanımıyla birlikte muhasebe açısından varolan beklentileri karşılayabilir olması beklenmektedir. Blok zincir teknolojisi günümüzde daha çok kripto paraların kayıt altına alındığı bir veritabanı olarak algılanmaktadır. Bununla birlikte, gelecekte finansal hizmetler, bankacılık ve muhasebe gibi birçok alanda önemli bir etkisi olacağ ifade edilmektedir. Çalışmada kullanılan veriler, hazırlanan bir anket formu aracılı̆̆ ile ülkemizde muhasebe alanında ögretim üyesi olarak görev yapmakta olan 121 akademisyenden toplanmıştır. Geliştirilen ölçeğin güvenilirliğini ve geçerliliğini değerlendirmek için doğrulayıcı faktör analizi (DFA) yapılmıştır. DFA sonuçları, geliştirilen ölçeğin "şeffalık”, "düşük maliyet", "verimlilik ve güvenlik", “denetim”ve "mevzuata uygunluk” olmak üzere 5 boyutlu bir yapıdan oluştuğunu ve bir bütün olarak önerilen yapının geçerli ve güvenli olduğunu ortaya koymuştur.

Anahtar Kelimeler: Endüstri 4.0, Blok Zincir, Doğrulayıcı Faktör Analizi, Muhasebe.

JEL Sınıflandırması: M15, M41, O14, O33.

\begin{abstract}
A Scale Development Study to Determine Perceptions Regarding the Use of Blockchain Technology in Accounting

\section{ABSTRACT}

This study aims to determine the perceptions about the usability of blockchain technology in accounting processes and to develop a scale to determine these perceptions. Security, confidentiality, auditing, customer satisfaction and regulatory requirements are extremely important concepts in accounting business and transactions. It is thought that these concepts will be able to meet the existing expectations in terms of accounting with the use of Blockchain technology. Blockchain technology is currently perceived as a database where mostly crypto coins are recorded. However, it is stated that it will have a significant impact in many areas such as financial services, banking and accounting in the future. The data used in the study were collected from 121 academicians who are experts in accounting in our country, via a questionnaire prepared. Confirmatory factor analysis (CFA) was conducted to evaluate the reliability and validity of the developed scale. CFA results revealed that the scale developed consists of a 5-dimensional structure including "transparency", "low cost", "efficiency and safety", "audit" and "compliance with legislation" and that the proposed structure as a whole is valid and safe.
\end{abstract}

Keywords: Industry 4.0, Blockchain, Confirmatory Factor Analysis, Accounting.

Jel Classification: M15, M41, O14, O33.

\footnotetext{
* Bu makale, 23-25 Nisan 2021 tarihleri arasında gerçekleştirilen VI. Uluslararası Muhasebe ve Finans Sempozyumunda bildiri olarak sunulmuştur.

Makaledeki araştırma için Erzincan Binali Yıldırım Üniversitesi İnsan Araştırmaları Etik Kurulu'nun 30/06/2021 tarihli ve 07/13 protokol nolu kararı ile etik açıdan uygun bulunmuştur.

Makale Gönderim Tarihi: 04.06.2021, Makale Kabul Tarihi: 13.07.2021, Makale Türü: Nicel Araştırma

** Dr. Öğr. Üyesi, Erzincan Binali Yıldırım Üniversitesi, mehmetguner@gmail.com, ORCID: 0000-0002-95231519.
} 


\section{GİRiş}

Son yıllarda toplumumuz, "Endüstri 4.0" olarak adlandırılan farklı endüstriler arasında yayılan yenilikçi bir teknoloji dalgasının ortaya çıkışını deneyimlemiştir. İlk yıllarda Endüstri 4.0 kavramı sadece imalat sektörünün ilgilendiği bir kavram olarak algılanmış ve birçok işletme bu teknoloji sayesinde önemli bir performans artışı sağlamıştır. Günümüzde ise, üretim işletmelerinin yanında telekominikasyondan bankacılığa kadar pek çok hizmet sektörü işletmesi de artık Endüstri 4.0'ın sunduğu dijital teknolojilerden fayda beklemektedir. Bulut teknolojileri, 3 boyutlu baskı, nesnelerin interneti, yapay zeka ve blok zinciri gibi teknolojiler Endüstri 4.0 devrimi kapsamına ortaya çıkmış ve birçok alanda kullanılmaya başlamıştır (Garg vd., 2021: 1).

Entüstri 4.0'ın toplumun kullanımına sunduğu önemli teknolojilerden birisi de blok zinciri teknolojisidir. Başlangıçta, bir kripto para birimi olan Bitcoin'in altyapısını oluşturmak için 2008 y1lında Satoshi Nakamoto adlı bir kişi ya da grup tarafından geliştirilen blok zinciri bir işlemin aracılar olmaksızın gerçekleştirilebilmesini ve kayıt altına alınabilmesini sağlayan bir teknolojidir (Biswas ve Muthukkumarasamy, 2016: 1392; Kılınç, 2020:991; Doğan ve Ertugay, 2019: 1654). Bir tanım olarak ifade etmek gerekirse; blok zinciri bir ağdaki tüm katılımcılar tarafından paylaşılan kriptografik olarak imzalanmış ve geri alınamaz işlem kayıtlarının sürekli genişleyen ve birbirine bağlı listesidir (Gartner, 2018; Garg vd.; 2021: 2).

Blok zinciri, işlemleri iki veya daha fazla taraf arasında kaydedebilen dağıtılmış bir defter teknolojisidir. Sistem, bu yapı sayesinde, gerçekleşen her işlemin işleme taraf olan ve ağa dahil tüm kullanıcılar tarafından izlenebilmesini sağlamaktadır. Sisteme veri girişi ancak ağda bulunan ve katılımcıların onayı ile bloklar halinde yapılabilir ve bir kez veri girişi yapıldığında işlem geriye alınamaz ya da değiştirilemez. Sistemin bu özelliği, bir yandan güvenilir bir veri ağı olmasını sağlarken, diğer yandan kullanıcıların merkezi bir düzenleyicinin olmadığı bir veri tabanında kayıt yapmasını sağlamaktadır (Kılınç, 2020: 990).

Finansal piyasalardaki birçok işlem için gün geçtikçe yaygın bir kullanım imkanı bulan blok zinciri teknolojisi, işletmelerde yürütülen faaliyetlerin bütünü için güvenilir bir teknolojik altyapı haline gelmeye başlamış ve neticede muhasebe alanında da kullanılması yönünde önemli çalışmalar yapılmaya başlanmıştır. Kayıtların silinemez ve değiştirilemez yapısı blok zinciri teknolojisinin dijital bir büyük defter (defter-i kebir) olarak kullanılmasını da beraberinde getirmiştir. Bu haliyle sistemin, geleneksel kayıt sistemlerinin alternatifi olabileceği, muhasebe verilerinin korunmasını ve gizliliğini sağlayacağı ve taraflar arasındaki işlemlerin kolaylıkla karşılaştırılabileceği gibi önemli avantajlar sunacağı düşünülmektedir. Ayrıca, zincire yapılan kayıtların, işlem taraflarının tamamının onayı olmadan değiştirilmesinin mümkün olmaması hata ve hile ihtimalini neredeyse ortadan kaldıracaktır. Yetki verilen tüm tarafların işlemlerle ilgili blok kayıtlarına erişiminin mümkün olması denetim etkinliğini de beraberinde getirecektir (Kurnaz, 2019: 162). Sistemin muhasebede kullanımı ile birlikte koşulları önceden tespit edilen faaliyetler bilgisayar tarafından otomatik olarak gerçekleştirilecek ve böylelikle hem maliyet tasarrufu sağlanacak hem de operasyonel anlamda sadeleşme ile birlikte tüm süreçlerde verimlilik artacaktır (Özdoğan ve Karğın, 2018: 168).

Blok zinciri teknolojisinin muhasebe alanında sağlayacağı avantajların doğru algılanması sistemin gelecekte kullanımının yaygınlaşması anlamında önem arz etmektedir. 
Özellikle, muhasebe alanında çalışan akademisyenlerin ve meslek mensuplarının muhasebenin geleceğinde önemli bir yer edineceği düşünülen teknolojiye bakış açılarının tespit edilmesi sistemin kullanılabilirliğine ve yaygınlaşmasına katkı sağlayacaktır. Bu çalışma, blok zinciri teknolojisinin muhasebe süreçlerinde kullanılabilirliğine yönelik bakış açılarının tespit edilmesi amacıyla bir ölçek geliştirmeyi ve bu ölçek aracılığı ile muhasebe öğretim üyelerinin sistemle ilgili algı düzeyini ortaya koymayı amaçlamaktadır. Çalışmada geliştirilen ölçekteki ifadelerin ifadelerin tasarlanan yapının tamamını temsil edebilecek faktörler olarak ifade edilmesi için keşfedici/açıklayıcı faktör analizi (AFA) yapılacak, AFA ile tespit edilen faktörlerin, dolayısıyla bir bütün olarak ölçeğin yap1 geçerliliğinin ortaya konulması için doğrulayıcı faktör analizi (DFA) yapılacaktır.

\section{KAVRAMSAL ÇERÇEVE}

Karmaşık bir küresel ağ olan internet, sunduğu birçok uygulama ile dünyamızı değiştirmiş ve bilgi alışverişinde devrimsel etkiler oluşturmuştur. İnternetin ortaya çıkardığı bu dijital devrim, günümüzde anonim olma beklentileri, veri güvenliği ihtiyacı ve yasal otoritelerin engellemelerine maruz kalmama düşüncesi ile bilginin her türlü kötü niyetli siber saldırıya karşı korumalı bir şekilde kaydedildiği bir eşler arası (peer-to-peer) dağıtılmış ya da dağıtık ağ olan blok zincirinin geliştirilmesini beraberinde getirmiştir. Blok zincir teknolojisinin dijital çağda iş ve toplum üzerinde önemli bir etki olacağı düşünülmekte, dolayısıyla hem akademisyenlerin hem de uygulamacıların ilgisini çekmektedir (Bonson ve Bednarova, 2019: 725).

\subsection{Blok Zincir Teknolojisi}

Blok zinciri, ağdaki her sunucunun sistemin bir kopyasına sahip olduğu, genel veya özel bir ağ üzerinden erişilebilen, oldukça güvenli, dağıtılmış ya da dağıtık bir defter sistemi türüdür. Dağıtık defter sistemi, eş zamanlı erişim, doğrulama ve güncelleme işlemlerinin değiştirilmeyecek bir şekilde yapılmasını sağlayan teknolojik alt yapı olarak ifade edilebilir. Bir başka anlatımla, verinin bütün halinden ziyade parçalanarak farklı merkezlerde saklandığ ve bu sayede herhangi bir kanun koyucu veya yönetimce kontrol edilmesinin engellendiği sistemdir (Şuekinci ve Çatıkkaş, 2020: 53). Sistemde veriler ağdaki tüm sunucular arasında gerçek zamanlı olarak çoğaltılır ve şifrelenir. Veriler her kaydedildiğinde (yetkili bir kullanıcıdan, cihazdan veya sisteme bağlı makineden), mutabakata dayalı bir mekanizma tarafından doğrulanır, zaman damgası vurulur ve bir defter sayfası olarak nitelendirilebilecek bir tür veri dosyası olan bloğa kaydedilir. Verilerin değiştirilmesini engellemek için her blok, bir şifreleme algoritması ile bir önceki bloğa eklenir veya bağlanır. Verileri değiştirmek isteyen bir bilgisayar korsanının mutabakat mekanizması ve karma algoritmalar nedeniyle çok daha yüksek bir karmaşıklık düzeyiyle karşı karşıya kalacak olması, ayrıca tüm sunuculara aynı anda saldırması gerekeceği için sistem son derece güvenlidir (Alarcon ve NG, 2018: 27).

Blok zincir teknolojisi, 2008 yılında, Satoshi Nakamoto adlı bir kişi ya da grup tarafindan dijital bir para birimi olan Bitcoin'in altyapısını oluşturmak üzere bir eşler arası ağ ve bir kurallar dizisini takip eden paylaşılan bir veri tabanı olarak geliştirilen sistemdir (Bonson ve Bednarova, 2019: 727). Ortaya çıkışından itibaren yaygınlaşmaya başlayan blok zincir teknolojisi son dönemlerde altyapısını oluşturduğu dijital para birimi Bitcoin'in ötesine geçmiş ve telekominikasyondan bankacılığa, hizmet sektöründen perakende sektörüne kadar birçok işletme alanında kullanılmaya başlayan ve aynı ölçüde de tartışılan bir kavram haline 
dönüşmüştür. Birçok alanda kullanılma imkanı olduğu düşünülen blok zincir, sürekli gelişen yapısı ve kullanılmaya başlanıldığı sektör ya da alanda evrimsel etkisi nedeniyle işletme düzeyindeki etkileri henüz tam olarak ortaya konulamamış bir teknolojidir (Uçma Uysal ve Kurt, 2018: 469).

Blok zincir, çok taraflı işlemlerin doğrulanarak kayıt altına alınması ve güvenli olarak depolanmasına dayalı bir teknolojidir. Basit olarak sistemin çalışması birbirinden tamamen bağımsız olan gelişmiş bilgisayarların ortak bir ağı kuracak şekilde internet tabanlı olarak birbirine bağlanması ile mümkün olmaktadır. Blok zincir kullanılarak yapılması planlanan işlem önce bu işlemi sisteme gönderen bir gönderici tarafindan şifreli olarak söz konusu ortak ağa sunulur ve aynı anda blok zincir ile ilgili yazılımları kullanan bilgisayarlar tarafindan görülür. Ortak ağı oluşturan bilgisayarlar konsensüs, bir başka ifade ile oybirliği ile çeşitli algoritmalar kullanmak suretiyle işlemin doğruluğunu ve geçerliliğini onaylarlar. Onaylanan yeni işlem İngilizce "hash" adı verilen bir blok oluşturacak şekilde benzeri olmayan bir şifreleme ile etiketlenir ve sistemde daha önce varolan bloklara zaman damgalı olarak eklenir. Ortaya çıkan yeni zincir ortak ağdaki tüm bilgisayarlar tarafından tanınır ve kaydedilir. Örnek bir para transferi üzerinden sistemin çalışma prensibi Şekil 1'de sunulmuştur (Gül, 2019: 187).

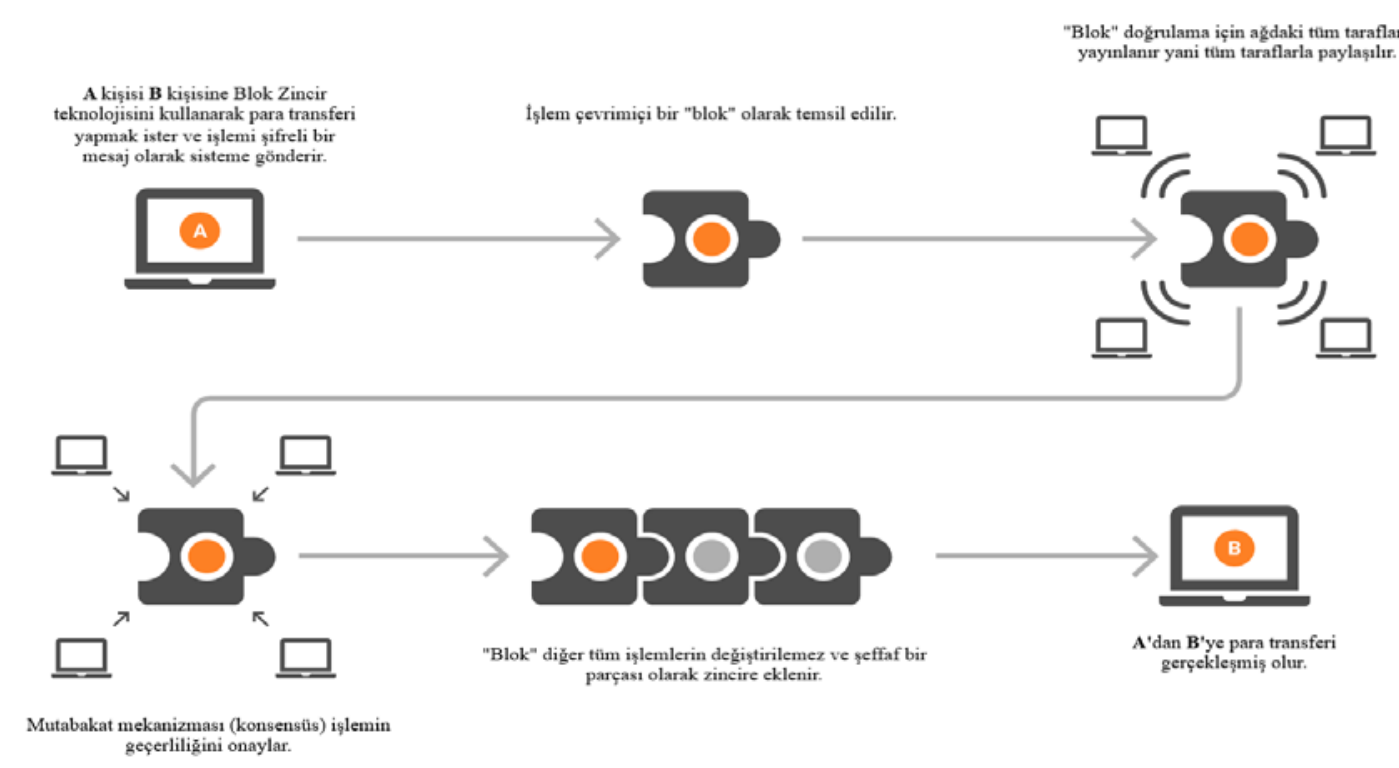

Şekil 1. Blok Zincir İşlem Süreci

Kaynak: Gül, 2019: 187

Blok zincir teknolojisinde onaylanarak zincire eklenen bir işlemin değiştirilmesi neredeyse imkansızdır. Çünkü, daha önce kaydedilen bir bloğu yani bir işlemi değiştirmek isteyen bir kullanıcı o bloktan sonraki tüm blokların benzersiz şifrelerini kırmak, değiştirmek istediği işlemi şifresini kırarak değiştirmek ve şifresini kırdığı bütün işlemleri yeniden sisteme eklemek zorundadır. Yaklaşık olarak her on dakikada sisteme yeni bir işlemin eklendiği sistemde kullanıcının tüm bu süreci tamamlaması için sadece on dakikası vardır. Dünya üzerinde, son derece güçlü bir şifreleme sistemi zaman damgalı olarak birbirine bağlanmış 
olan böyle bir sistemi bu kadar kısa süre içerisinde deşifre edebilecek bir bilgisayar sistemi bulunmadığı düşünüldüğünde zincire eklenmiş bir işlemin değiştirilmesinin büyük ölçüde imkansız olduğu da anlaşılmaktadır (Gül, 2019: 189).

Blok zincir teknolojisinin mimarisi dört temel tasarım kararına dayalıdır. Bunlar kontrol, veri sahipliği, gizlilik ve erişim ile ilgili karar unsurlarıdır. Tasarım aşamasında söz konusu unsurlarla ilgili verilecek kararlar aynı zamanda blok zincir teknolojisinin türünü de ortaya koyar. Blok zincir teknolojisinin genellikle birbiriyle çelişen sınıflandırması söz konusudur. Temel olarak, sistemde işlem yapmak için yetkilendirmenin gerekip gerekmediği kriteri ile verilere erişim imkanı kriterine göre blok zincir dört alt sınıfa ayrılabilir. Yetkilendirmenin gerekip geremediğine göre blok zincir tasarımı iki şekilde yapılabilir (Peters ve Panayi, 2015: 5):

İzinsiz Blok Zincir (Permissionless Blockchain): Herhangi bir kişinin önceden izin gerekmeksizin doğrulama sürecine katılabileceği ve kullanıcının genellikle parasal bir ödül karşılığında hesaplama gücüne katkıda bulunabileceği blok zincir türüdür.

- İzinli Blok Zincir (Permissioned Blockchain): Doğrulama sürecine katılabilecek olan kişilerin merkezi bir otorite veya konsorsiyum tarafindan önceden seçildiği blok zincirdir.

Blok zincir tasarımı verilere erişim imkanına göre ise şu şekillerde ortaya çıkabilir (Peters ve Panayi, 2015: 5):

Halka Açık Blok Zincir (Public Blockchain): Herkesin blok zincirindeki işlemleri okuyabildiği ve zincire yeni işlemler gönderebileceği blok zincirdir.

- Özel Blok Zincir (Private Blockchain): Erişim iznini kuruluş veya kuruluş grubu içindeki kullanıcılarla sınırlı olduğu blok zincir türüdür.

Temelde blok zincir mimarisi özel yerine halka açık, izinsiz yerine izinli şekilde tasarlanmalıdır. Kontrol ne kadar büyük olursa, blok zinciri mimarisi ilk vizyonundan o kadar uzaklaşmaktadır. Bununla birlikte özel ve izinsiz blok zincir tasarımına ihtiyaç duyulan özel uygulamalar olması da doğaldır (Mainelli ve Smith, 2015: 8).

\subsection{Blok Zincir Ve Muhasebe}

Nesnelerin interneti tabanlı teknolojiler, yönetim ve muhasebe prosedürlerinin koşullarını yeniden belirlemekte, bilginin paylaşılması, toplanması ve dağıtılması yollarını değiştirerek yeni bir muhasebe altyapısının ortaya çıkmasına neden olmaktadır. Halihazırda, muhasebe alanında nesnelerin interneti alanındaki yenilikçi gelişmelerin uygulanması, mümkün olan en kısa sürede büyük bilgi dizilerini işleme firsatı sunmaktadır. Söz konusu teknolojilerin kullanımı yalnızca verilerin işlenmesini ve analizini hılandırmakla kalmayacak, aynı zamanda muhasebe, denetim ve raporlama şeffaflığında küresel eğilimler uygulanmasını da sağlayacaktır. Nesnelerin interneti teknolojilerinden birisi olan blok zinciri muhasebede ihtiyaç duyulan şeffaflık, kalite ve yüksek düzeyde bilgi koruması gibi gereksinimleri karşılayabilecek bir sistem olarak görülmektedir (Kwilinski, 2019: 1).

Blok zincir teknolojisinin finansal piyasalarda günden güne yaygınlaşan kullanımı birçok işletme fonksiyonunun yürütülmesi için alternatif bir teknoloji halini alması 
işletmelerin muhasebe ve denetim süreçleri için kullanılabilirliğini de beraberinde getirmiştir. Özellikle, silinemez ve değiştirilemez kayıt yapısı ve ilgili tüm tarafların kayıtlara erişim imkanına sahip olması, veri güvenliği ve şeffaflık anlamında geleneksel muhasebe kayıt düzenine göre önemli bazı avantajları beraberinde getirmektedir. Sistemin, ticari taraflar arasındaki muhasebe kayıtlarını hızlı ve kolay bir şekilde karşılaştırılabilir kılması dolayısıyla hem hata ve hileye izin vermemesi hem de mutabakat sürecini ortadan kaldırması, muhasebe işlem süreçlerinin etkinliğini artırmak suretiyle zaman ve maliyet tasarrufu sağlayabilecektir. Blok zincir teknolojisi kullanılarak muhasebe süreçlerinin takip edilmesi, doğrulanarak zincire kaydedilen bir bloğun değiştirilemez yapısı nedeniyle muhasebe işlemleri anlamında operasyonel sadeleşmeyi de beraberinde getirecektir. Ayrıca, işletme içinden ve dişından yetki verilen tüm kullanıcıların işlem verilerine erişebiliyor olması denetiminin etkinliğini ve verimliliğini artıracaktır (Özdoğan ve Karğın, 2018: 168). Özellikle, kamuya açık ve izinli blok zincir tasarımlarında verilerin herkes tarafından erişilebilir olarak sunulması imkanı, kamuoyu ve yasal otoritelerin gözetleyici baskısından dolayı işlem ve kayıt süreçlerinin mevzuata uygunluğunu da artıracaktır. Blok zincir teknolojisinin muhasebe süreçlerinde kullanımı kısaca şu avantajlara sahiptir (Vijai vd., 2019: 553; Şuekinci ve Çatıkkaş, 2020: 58):

- Daha hızlı süreçler ile artan verimlilik: İşlemlerin yüksek teknolojik altyapı sayesinde gerçek zamanlı olarak ve birden çok taraf arasında kaydedilmesi sayesinde zamandan ve maliyetten tasarruf sağlayacaktır.

- Güvenlik: Kötü niyetli müdahalelere karşı dayanıklı bir teknoloji olduğunda verilerin güvende tutulmasına imkan verecektir.

- Şeffaflık: Paydaşlara ihtiyaç duydukları finansal bilginin daha hızlı, doğru ve dürüst bir şekilde sunulmasını mümkün kılacaktır.

- Denetimde basitleştirme ve etkinlik: İşlemlerin yetkilendirme yoluyla paylaşımı sayesinde denetim süreçlerinin daha sade olmasını ve daha kısa sürede az maliyetle yürütülmesini sağlayacaktır.

- Hata ve hilenin azaltılması veya tamamen ortadan kalkması: Mutabakat mekanizması, eşler arası kayıt süreçleri ve akıllı sözleşmeler sayesinde insan hatası ortadan kalkabilir ve hilenin önüne geçilebilecektir. sağlanabilecektir.

Maliyet tasarrufu: Verimlilik artışı neticesinde süreç maliyetlerinin azalması

Mevzuata uygunluğun artış1: Gelişmiş güvenlik sistemleri sayesinde mevzuat gereksinimlerini karşılamak mümkün olabilecektir.

\section{METODOLOJI}

Blok zincir teknolojisi muhasebe alanında henüz oldukça yeni bir kavramdır. Ancak, yakın gelecekte muhasebenin önemli bir unsuru olacağı düşünülmekte ve uluslararası muhasebe kuruluşları tarafından sistemin muhasebede kullanılabilirliği ile ilgili çalışmalar yapılmaktadır. Muhasebenin geleceğinde bu denli önemli bir yer edineceği düşünülen blok zincir teknolojisine yönelik bakış açılarının ve algıların tespiti de bu anlamda önem arz etmektedir. Çalışmanın bu kısmında, söz konusu algıların tespitine yönelik bir ölçek geliştirilmesi ile ilgi yapılan saha çalışması ile ilgili hususlar anlatılacaktır. 


\subsection{Araştırmanın Amacı Ve Önemi}

$\mathrm{Bu}$ çalışmanın amacı, blok zinciri teknolojisinin muhasebe alanında kullanılmasına yönelik algıların tespit edilebilmesi için geçerli ve güvenilir bir ölçek geliştirmektir. Ayrıca, veri kaynağı olarak belirlenen muhasebe alanında uzman öğretim üyelerinin blok zinciri teknolojisinin muhasebe süreçlerinde kullanılabilirliğine ilişkin algı düzeyinin ortaya konulması da çalışmanın bir diğer amacı olarak ifade edilebilir.

Literatür taramaları, blok zinciri teknolojisinin muhasebe alanında kullanımında sağlayabileceği faydalar anlamında öne çıkan önemli bazı hususları ortaya koymaktadır. İşletmelerin muhasebe çıktılarından yararlanan paydaşlara yönelik bilgilendirmelerin daha kolay, hızlı ve şeffaf bir şekilde yürütülebilecek olması; şeffaflıkla birlikte müşteri hizmetleri kalitesinde ve buna bağlı olarak müşteri memnuniyetinde artış sağlanabilecek olması; tüm muhasebe süreçlerinin daha düşük maliyetlerle takip edilebilecek olması; maliyetlerdeki düşüş neticesinde muhasebe kayıt sürecinin verimliliğinin artabileceği; özellikle sistemin sağlayacağı değiştirilemez kayıt sistemi sayesinde muhasebe kayıtlarının güvenliğinin maksimum düzeye çıkabilecek olması; daha etkili, verimli ve hızlı bir denetim sürecinin mümkün olması ve sistemin sağlayacağı şeffaflıkla birlikte mevzuat hükümlerine uyum düzeyinin artacağı, hata ve hilelerin minimuma indirilebileceği hatta tamamen ortadan kalkabileceği gibi hususlar sistemin muhasebe açısından sağlayacağı düşünülen faydalardan en önde gelenleridir ve blok zinciri teknolojisinin muhasebenin geleceği için önemini ortaya koymaktadır (Fanning ve Centers, 2016: 55; Özdoğan ve Karğın, 2018: 169; Alarcon ve Ng, 2018: 28; Gül, 2019: 189; Şuekinci ve Çatıkkaş, 2020: 58).

\subsection{Araştırmanın Yöntemi}

Bu çalışma, anket yöntemi ile veri toplanması ve analiz edilmesine yönelik keşifsel bir araştırmadır. Elde edilen veriler SPSS ve Lisrel paket programları aracılığı ile analiz edilmiştir. Geliştirilen ölçekteki ifadelerin yapının bütününü temsil eden daha az sayıdaki faktöre indirgenmesi için öncelikle keşfedici/açıklayıcı faktör analizi (AFA) yapılmış sonrasında AFA'nın ortaya koyduğu yapının geçerliliği doğrulayıcı faktör analizi (DFA) ile sınanmıştır. Ayrıca, akademisyenlerin muhasebede blok zinciri kullanılabilirliğine yönelik algılarını ortaya koymak amacıyla boyut ortalamalarından ve bir bütün olarak ölçek ortalamasından yararlanılmıştır.

Araştırmanın kapsamını akademik çalışmalarını muhasebe alanında sürdüren öğretim üyeleri oluşturmaktadır. Araştırmanın yapılabilmesi için Erzincan Binalı Yıldırım Üniversitesi İnsan Araştırmaları Etik Kurulu Başkanlığından onay alınmıştır. Anketlerin uygulanmaya başlandığı Ocak 2021 tarihi itibarı ile Yükseköğretim Akademik Arama (YÖK Akademik) internet sayfasında muhasebe alanında görev yapan öğretim üyesi sayısı 650 olarak tespit edilmiştir. 121 öğretim üyesinden uygun geri dönüş alınmıştır. Bu çerçevede, örneklemin \% 95 güven seviyesinde ve yaklaşık \% 8 hata payı ile evreni temsil ettiği söylenebilir (https://www.openepi.com/SampleSize/SSPropor.htm, 2021).

Araştırmada analiz edilecek verilerin toplanması için araştırmacı tarafından 5'li Likert tipi yanıtları içeren 25 sorudan oluşan bir anket formu oluşturulmuştur. Anket formunun oluşturulmasında literatürde yer almış blok zincirine yönelik çalışmalardan yararlanılmıştır. Özellikle, Garg vd. (2021) tarafından blok zinciri teknolojisinin bankacilık sektöründe 
kullanımına yönelik algıların tespit edilmesi için geliştirilen anket ve Walsh vd. (2021) tarafindan finansal hizmetler sektöründeki yöneticilerin blok zincirine yönelik dirençlerinin analiz edildiği çalışmada kullanılan anket, soruların oluşturulması için rehber olmuştur.

\subsection{Araştırmanın Bulguları}

\subsubsection{Demografik Özellikler İle İlgili Bulgular}

Araştırmaya katılan akademisyenlerin demografik özelliklerine ilişkin bulgulara göre; anketi yanıtlayan öğretim üyelerinin 78'i (\% 64,5) erkek, 43'ü (\% 35,5) ise kadındır. Yaş dağılımı incelendiğinde 25-35 yaş arası akademisyenlerin 39 (\% 32,2) kişi, 36-45 yaş aralığındakilerin $55(\% 45,5)$ kişi, 46-55 yaş arasında olanların $20(\% 16,5)$ kişi ve 55 yaş üstü akademisyenlerin ise $7(\% 5,8)$ kişi olduğu görülmüştür. Ünvana göre dağılıma bakıldığında ise, profesör doktor $12(\% 9,9)$, doçent doktor $30(\%$ 24,8) ve doktor öğretim üyesi 79 (\% 65,3) olarak gerçekleşmiştir.

Araştırmanın önemli bulgularından birisi anketi yanıtlayan akademisyenlerin blok zincir teknolojisi ya da bu teknolojinin muhasebede kullanımı ile bir eğitim alıp almadıklarına ilişkin soruya verilen yanıtlardır. Katılımcıların büyük çoğunluğunun $(109$ kişi - \% 90,1) konu ile ilgili bir eğitim almadıkları, sadece 12 (\% 9,9) katılımcının eğitim aldıkları tespit edilmiştir. Ayrıca, blok zincir teknolojisinin muhasebede kullanımı ile ilgili yayın yapmış olan akademisyen sayısı da sadece $13(\%$ 10,7) olarak belirlenmiştir. Blok zincir teknolojisinin muhasebede kullanımı ile ilgili çalışmaların henüz tasarım aşamasında olması ve uygulamaya geçirilmemiş olması bu konudaki eğitim ve yayınların da henüz yaygınlaşmadığı sonucunu doğurduğu, dolayısıyla akademisyenlerin de bu konudaki eğitim alma ve yayın yapma oranlarının bu nedenle düşük olduğu düşünülmektedir. Öte yandan, blok zincir teknolojisinin muhasebede kullanımıyla ilgili daha fazla kişinin katkısının ve düşüncelerinin alınması için yapılan toplantıların (kongre, sempozyum, panel, webinar vb.) gün geçtikçe arttığı gözlenmektedir. Nitekim, katılımcıların 45'i $(\% 37,2)$ konu ile ilgili bir toplantıya katıldıklarını beyan etmişlerdir. Düzenlenen etkinlik sayısının artmasının bu konudaki farkındalığı artıracağı düşünülmektedir.

\subsubsection{Geçerlilik, Güvenilirlik Ve Faktör Analizine İlişkin Bulgular}

Geliştirilen ölçekteki soruların ortaya koyduğu yapının daha az sayıda faktörle ifade edilebilmesi için açıklayıcı faktör analizi (AFA) yapılmıştır. Kaiser-Meyer-Olkin (KMO) Örneklem Yeterliliği Ölçüsü'nün 0,868 olması ve Bartlett'in küresellik testi değerlerinin anlamlı olması (Sig. = 0,000) ölçeğin bir bütün olarak faktör analizine uygun olduğunu ortaya koymuştur.

Her bir soruya ilişkin faktör yük değerlerinin sunulduğu Tablo 1'de görüldüğü üzere faktör analizi sonucunda "denetim (D)”, "verimlilik ve güvenlik (VG)”, “mevzuata uygunluk (MU)", "şeffaflık (ŞEF)" ve "düşük maliyet (DM)" olmak üzere 5 faktör ortaya çıkmıştır ve açıklanan toplam varyans 67,495'tir. Faktörlerin güvenilirlik değerleri Cronbach's Alpha değeri ile ortaya konulmuştur ve sırasıyla \% 94,3 (D), \% 86,2 (VG), \% 82,3 (MU), \% 90,1 (ŞEF), \%83,4 (DM) olarak tespit edilmiştir. Bir bütün olarak ölçek sorularının tamamına ilişskin güvenilirlik katsayısı ise \% 93,1'dir. 
Tablo 1. Açıklayıcı Faktör Analizi (AFA) Sonuçları

\begin{tabular}{|c|c|c|c|c|c|}
\hline \multirow[b]{2}{*}{ Sorular } & \multicolumn{5}{|c|}{ Faktörler } \\
\hline & $\begin{array}{l}\text { Denetim } \\
\text { (D) }\end{array}$ & $\begin{array}{l}\text { Verimlilik } \\
\text { ve } \\
\text { Güvenlik } \\
\text { (VG) }\end{array}$ & $\begin{array}{l}\text { Mevzuata } \\
\text { Uygunluk } \\
\text { (MU) }\end{array}$ & $\begin{array}{l}\text { Şeffaflık } \\
\text { (ŞEF) }\end{array}$ & $\begin{array}{l}\text { Düşük } \\
\text { Maliyet } \\
\text { (DM) }\end{array}$ \\
\hline $\begin{array}{l}\text { D1. Muhasebede blok zincir teknolojisinin kullanılmas1 } \\
\text { denetim etkinliginini artıracaktır. }\end{array}$ & 0,905 & & & & \\
\hline $\begin{array}{l}\text { D5. Muhasebede blok zincir teknolojisinin kullanılmas1 } \\
\text { veriler üzerindeki kontrol gücünü artıracaktır. }\end{array}$ & 0,899 & & & & \\
\hline $\begin{array}{l}\text { D3. Muhasebede blok zincir teknolojisinin kullanılması } \\
\text { hızlı ve güvenli bir ödeme süreci sağlayacaktır. }\end{array}$ & 0,786 & & & & \\
\hline $\begin{array}{l}\text { D2. Muhasebede blok zincir teknolojisinin kullanılmas1 } \\
\text { denetim süreçlerini kolaylaştıracaktır. }\end{array}$ & 0,549 & & & & \\
\hline $\begin{array}{l}\text { VG2. Muhasebede blok zincir teknolojisinin kullanılması } \\
\text { işlem hızını artıracaktır. }\end{array}$ & & 0,821 & & & \\
\hline $\begin{array}{l}\text { VG5. Muhasebede blok zincir teknolojisinin kullanılması } \\
\text { muhasebe sistemlerinin bütünleşmesine katkı } \\
\text { sağlayacaktır. }\end{array}$ & & 0,819 & & & \\
\hline $\begin{array}{l}\text { VG1. Muhasebede blok zincir teknolojisinin kullanılması } \\
\text { gerçek zamanlı ticari işlemlerin izlenmesine yardımcı } \\
\text { olarak muhasebe süreçlerindeki olası gecikmeleri } \\
\text { engelleyecektir. }\end{array}$ & & 0,811 & & & \\
\hline $\begin{array}{l}\text { VG3. Muhasebede blok zincir teknolojisinin kullanılmas1 } \\
\text { etkinliği artıracaktır. }\end{array}$ & & 0,512 & & & \\
\hline $\begin{array}{l}\text { MU6. Muhasebede blok zincir teknolojisinin kullanılması } \\
\text { hataları azaltacaktır. }\end{array}$ & & & 0,790 & & \\
\hline $\begin{array}{l}\text { MU5. Muhasebede blok zincir teknolojisinin kullanılmas1 } \\
\text { mevzuata uygunluğu artıracaktır. }\end{array}$ & & & 0,654 & & \\
\hline $\begin{array}{l}\text { MU3. Muhasebede blok zincir teknolojisinin kullanılması } \\
\text { hileyi önleyecektir. }\end{array}$ & & & 0,631 & & \\
\hline $\begin{array}{l}\text { MU4. Muhasebede blok zincir teknolojisinin kullanılması } \\
\text { verilerin gizliliği ve korunmasını sağlayacaktır. }\end{array}$ & & & 0,507 & & \\
\hline $\begin{array}{l}\text { MU1. Muhasebede blok zincir teknolojisinin kullanılması } \\
\text { iş süreçlerini kolaylaştıracaktır. }\end{array}$ & & & 0,466 & & \\
\hline $\begin{array}{l}\text { ŞEF2. Muhasebede blok zincir teknolojisinin kullanılması } \\
\text { muhasebe süreçlerine yönelik müşteri güvenini } \\
\text { artıracaktır. }\end{array}$ & & & & 0,807 & \\
\hline $\begin{array}{l}\text { ŞEF1. Muhasebede blok zincir teknolojisinin kullanılması } \\
\text { şeffaflığı artıracaktır. }\end{array}$ & & & & 0,764 & \\
\hline $\begin{array}{l}\text { ŞEF4. Muhasebede blok zincir teknolojisinin kullanılması } \\
\text { bilgilendirmede riski azaltacaktır. }\end{array}$ & & & & 0,643 & \\
\hline $\begin{array}{l}\text { SSEF3. Muhasebede blok zincir teknolojisinin kullanılması } \\
\text { taraflar (işletme-müşteri) arasındaki eylemleri ve işlemleri }\end{array}$ & & & & 0,556 & \\
\hline
\end{tabular}




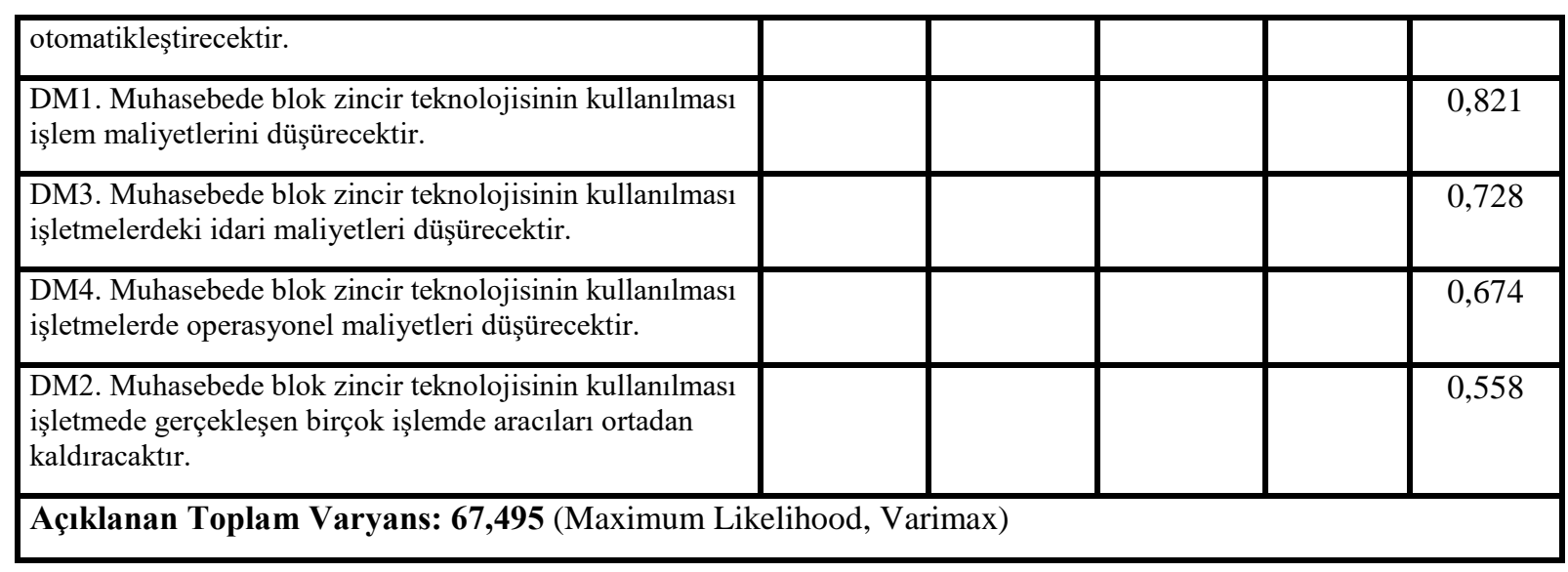

Blok zinciri teknolojisinin muhasebede kullanımına yönelik algıların tespiti amacıyla oluşturulan anketin AFA ile ortaya konulan faktörlerinin yapı geçerliliğinin test edilmesi, bir başka ifade ile söz konusu algıları ölçebilecek geçerli bir yapı (ölçek) olup olmadığının ortaya konulması amacıyla Lisrel programı aracılığıyla doğrulayıcı faktör analizi (DFA) yapılmıştır. Şekil 1, DFA sonuçlarını göstermektedir.

Doğrulayıcı Faktör Analizinde, model uygunluğunun ortaya konulması bir başka ifade ile oluşturulan modelin geçerli bir model olup olmadığının tespit edilmesi için çeşitli uyum iyiliği indeksleri kullanılmaktadır. Bunlar aşağıdaki gibi sıralanabilir (Arı, 2015: 555):

1- $\quad$ Ki-kare/serbestlik derecesi $(\chi 2 / \mathrm{df})$

2- $\quad$ Düzeltilmiş Uyum İndeksi (Adjusted Goodness of Fit Index- AGFI)

3- $\quad$ Normalleştirilmiş Uyum İyiliği İndeksi (The Normed Fit Index- NFI)

4- Bağıl Uyum İndeksi (Relative Fit Index- RFI)

5- $\quad$ Artmalı Uyum İndeksi (Incremental Fit Index- CFI)

6- $\quad$ Uyum İyiliği İndeksi (Goodness of Fit Index-GFI)

7- Ortalama Hata Kök Yaklaşımı (Root-mean-square error approximationRMSEA). 


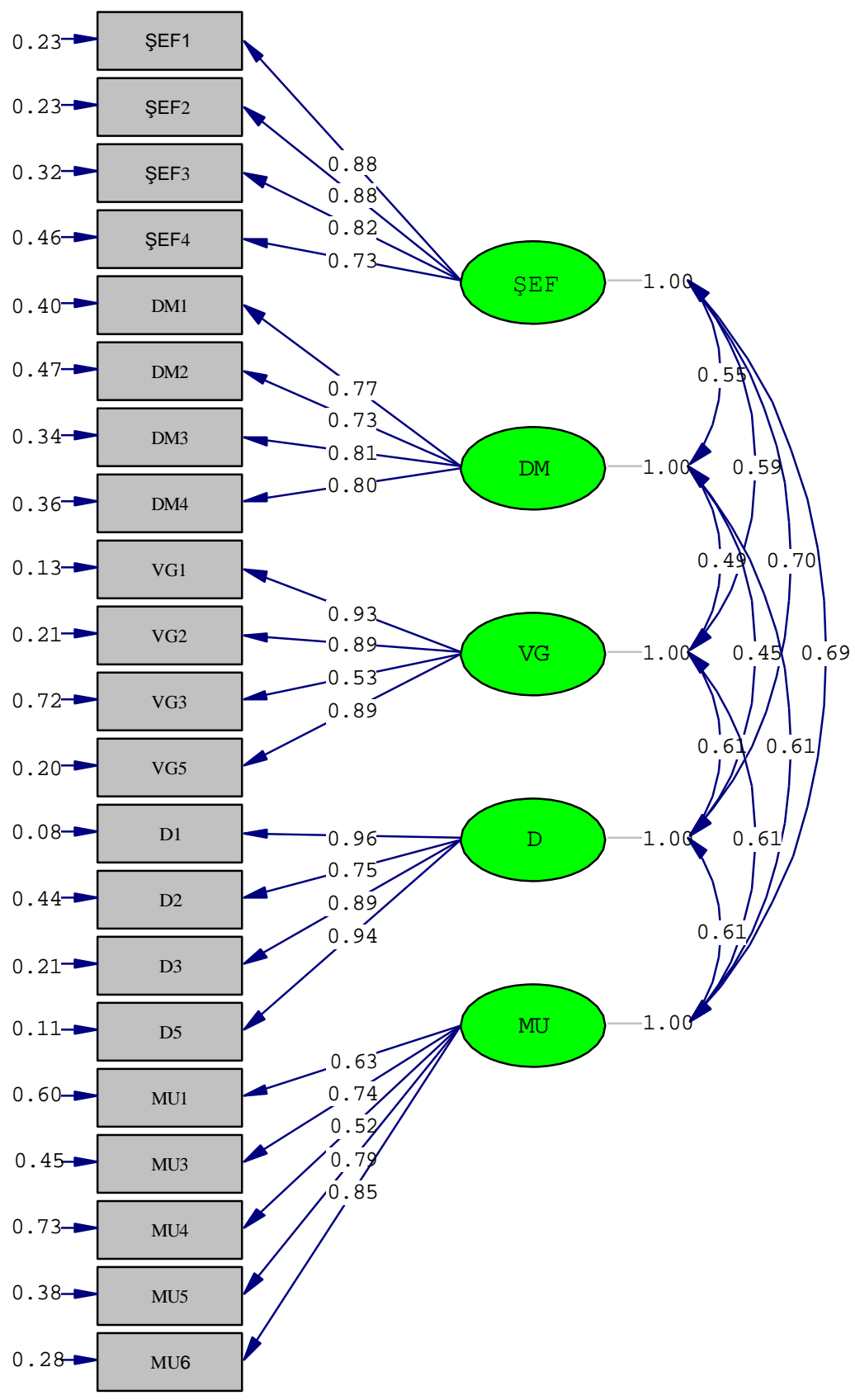

Chi-Square=293.85, $d f=179, \quad P-$ value $=0.00000, \quad$ RMSEA $=0.073$

Şekil 1. Doğrulayıcı Faktör Analizi (DFA) Sonuçları

Uyum iyiliği indekslerinin referans aralıkları ve elde edilen veriler çerçevesinde yapılan doğrulayıcı faktör analizine ilişkin uyum iyiliği değerleri Tablo 2'de sunulmuştur. Ayrıca, modele ilişkin t değerleri de incelenmiş ve AFA neticesinde ortaya çıkan yapıda soru eliminasyonunu gerektirecek bir değer gözlenmemiştir. 
Tablo 2'ye göre tüm uyum iyiliği değerleri modelin geçerli bir model olduğunu ortaya koymaktadır. Blok zinciri teknolojisinin muhasebe süreçlerinde kullanılabilirliğine yönelik algıların tespiti için oluşturulan ölçeğin, yapıyı oluşturan faktörlerin ortaya konulduğu açıklayıcı faktör analizi (AFA) ve bu faktörlerin oluşturduğu modelin geçerliliğinin test edildiği doğrulayıcı faktör analizi (DFA) sonuçlarına göre geçerli ve güvenilir bir ölçek olduğu, söz konusu algıların tespiti için kullanılabileceği ifade edilebilir.

Tablo 2. Uyum İyiliği İndeksleri Referans Aralıkları ve Çalışma Uyum İyiliği Bulguları

\begin{tabular}{|l|c|c|c|}
\hline \multicolumn{1}{|c|}{$\begin{array}{c}\text { Model Uyum } \\
\text { Kriteri }\end{array}$} & İyi Uyum & Kabul Edilebilir Uyum & Çalışma Bulguları \\
\hline$\chi 2 / \mathrm{df}$ & $0 \leq \chi 2 / \mathrm{df} \leq 2$ & $2<\chi 2 / \mathrm{df} \leq 3$ & $293,85 / 179=\mathbf{1 , 6 4}$ (İyi uyum) \\
\hline RMSEA & $0 \leq R M S E A \leq 0,05$ & $0,05 \leq R M S E A \leq 0,08$ & $\mathbf{0 , 0 7 3}$ (Kabul edilebilir uyum) \\
\hline CFI & $0,97 \leq C F I \leq 1$ & $0,95 \leq C F I \leq 0,97$ & $\mathbf{0 , 9 7}$ (İyi uyum) \\
\hline NFI & $0,95 \leq N F I \leq 1$ & $0,90 \leq N F I \leq 0,95$ & $\mathbf{0 , 9 3}$ (Kabul edilebilir uyum) \\
\hline GFI & $0,95 \leq G F I \leq 1$ & $0,90 \leq G F I \leq 0,95$ & $\mathbf{0 , 9 1}$ (Kabul edilebilir uyum) \\
\hline
\end{tabular}

Kaynak: Schermelleh-Engel vd., 2003:52.

Çalışmanın bir diğer amacı, muhasebe öğretim üyelerinin blok zincir teknolojisinin muhasebede kullanılabilirliğine yönelik algı düzeylerini ortaya koymaktır. Bu amaçla, ölçeğin her bir faktörüne verilen cevapların ortalaması ve ayrıca bir bütün olarak ölçeğe verilen yanıtların ortalamaları hesaplanmıştır. "Şeffaflık" faktörüne verilen cevapların ortalaması 4,0062, "düşük maliyet" faktörüne verilen cevapların ortalamas1 4,0702, "verimlilik ve güvenlik" faktörüne verilen cevapların ortalaması 4,2087, "denetim" faktörüne verilen cevapların ortalaması 4,1702, "mevzuata uygunluk" faktörüne verilen cevapların ortalaması 3,8198 olarak tespit edilirken bir bütün olarak ölçeğin tüm sorularına verilen cevapların ortalaması 4,0248 olarak hesaplanmıştır. $\mathrm{Bu}$ sonuçlar, muhasebe öğretim üyelerinin blok zincir teknolojisinin muhasebede kullanılabilir olduğuna ilişkin algılarının son derece yüksek olduğunu ifade etmektedir. Bununla birlikte, mevzuata uygunluk faktörü ortalaması görece diğer faktörlerden daha düşük bir ortalamaya sahiptir. Blok zincir teknolojisine yönelik henüz yasal bir mevzuatın olmayışının akademisyenlerin bu konuda daha temkinli yanıt vermelerine neden olduğu düşünülmektedir.

\section{SONUÇ}

Çalışmada, içerik geçerliliğinin sağlanması için kapsamlı bir literatür incelemesi ve yapı geçerliliğinin sağlanması için akademisyenlerden alınan görüşlere dayalı istatistiksel analizlerden oluşan doğrulama prosedürleri kullanılmıştır. Doğrulayıcı faktör analizi, oluşturulan ölçeğin yapı geçerliliğinin olduğunu ortaya koymuştur. 5'li Likert tipi değerlendirme içeren 21 ifadenin "şeffaflık", "düşük maliyet", "verimlilik ve güvenlik", "denetim" ve "mevzuata uygunluk" olmak üzere 5 faktörlü bir yapıda toplandığı bir ölçek ortaya çıkmıştır. Doğrulayıcı faktör analizi sonuçlarına göre, geliştirilen ölçeğin yapısal geçerliği olan ve güvenilir bir ölçek olduğu, blok zincir teknolojisinin muhasebede kullanılmasına yönelik algıların tespiti için kullanılabileceği ifade edilebilir. 
Her bir faktörde yer alan ifadelere verilen cevapların ortalamaları ile bir bütün olarak tüm sorulara verilen cevap ortalamaları, muhasebe alanında uzman akademisyenlerin blok zincir teknolojisinin muhasebede kullanılabilirliğine yönelik algılarının son derece yüksek olduğu ortaya koymuştur.

Blok zincir teknolojisinin muhasebede kullanılmasına yönelik olarak özellikle uluslararası muhasebe kuruluşları tarafından birçok çalışma ve araştırma yürütülmektedir. Muhasebenin geleceği olarak ifade edilen teknoloji henüz muhasebede kullanılması için hazır olmasa da özellikle mevzuat düzenlemeleri ile birlikte yakın gelecekte muhasebe uygulamaları için çok daha sık gündeme geleceği düşünülmektedir.

Gelecekte yapılacak çalışmalarda, özellikle muhasebe meslek mensuplarının teknolojinin kullanılabilirliğine yönelik düşünceleri geliştirilen ölçek yardımı ile tespit edilebilir ve bu konuda bir farkındalık oluşturulabilir.

\section{KAYNAKLAR}

Alarcon, L. John - Ng, Cory (2018), "Blockchain and the Future of Accounting”, Pennsylvania CPA Journal, Winter, ss. 26-29.

Arı, Erkan (2015), “Öğretmenlerin İş Doyumlarının Mesleki Tükenmişlik Üzerine Etkisinin Yapısal Eşitlik Modeli ile Araştırılması", Uluslararası Sosyal Araştırmalar Dergisi, 8(39), ss. 549-565.

Bonsón, Enrique - Bednárová, Michaela (2019), "Blockchain and Its Implications for Accounting and Auditing”, Meditari Accountancy Research, 27(5), ss.725-740.

Biswas, Kamanashis - Muthukkumarasamy, Vallipuram (2016), "Securing Smart Cities Using Blockchain Technology”, IEEE 18th International Conference on High Performance Computing and Communications; IEEE 14th International Conference on Smart City; IEEE 2nd International Conference on Data Science and Systems, ss. 1392-1393.

Doğan, Mustafa - Ertugay, Emrah (2019), "Blokzinciri ve Muhasebe Alanındaki Uygulamaları”, Üçüncü Sektör Sosyal Ekonomi Dergisi, 54(4), ss. 1654-1670.

Fanning, Kurt - Centers, David P. (2016), "Blockchain and Its Coming Impact on Financial Services”, The Journal of Corporate Accounting and Finance, 27(5), ss. 53-57.

Garg, Poonam - Gupta Bhumika - Chauhan, A. Kumar - Sivarajah, Uthayasankar - Gupta, Shivam - Modgil, Sachin (2021), "Measuring the perceived benefits of implementing blockchain technology in the banking sector", Technological Forecasting and Social Change, 163, ss. 1-18.

Gartner (2018), “Hype Cycle for Blockchain Technologies-2018”, https://www.gartner.com/en/documents/3883991/hype-cycle-for-blockchaintechnologies-2018, (Erişim Tarihi: 28.02.2021) 
Gül, Hasan (2019), “Blokzincir (Blockchain) Teknolojisi ve Muhasebe Bilgi Sistemine Etkileri”, Sosyal, Beşeri ve İdari Bilimlerde Yenilikçi Yaklaşımlar (pp.186-195), Bursa: Ekin Yayınevi.

Kwilinski, Aleksy (2019), "Implementation of Blockchain Technology in Accounting Sphere”, Academy of Accounting and Financial Studies Journal, 23 (Özel Say1 2), ss. $1-6$.

Kılınç, Yavuz (2020), "Blockchaın Teknolojisi: Muhasebe ve Denetim Mesleği Açısından Bir İnceleme”, Muhasebe ve Vergi Uygulamaları Dergisi, 13(3), 989-1011.

Kurnaz, Ersin (2019), "Bağımsız Denetçilerin Bakış Açısıyla Blokzincir (Blockchain) Teknolojisi”, M. Serçemeli (Ed.), Endüstri 4.0'ın Muhasebe, Denetim ve Finans Dünyasına Yansımaları, s. 157-173, Ankara: Gazi Kitabevi.

Mainelli, Michael - Smith, Mike (2015), "Sharing Ledgers for Sharing Economies: An Exploration of Mutual Distributed Ledgers (Aka Blockchain Technology)”, The Journal of Financial Perspectives, 3(3), ss. 38-69.

Özdoğan, Burak - Karğın, Sibel (2018), "Blok Zinciri Teknolojisinin Muhasebe ve Finans Alanlarına Yönelik Yansımaları ve Beklentiler", Muhasebe ve Finansman Dergisi, (80), ss. 161-176.

Peters, Gareth W. - Panayi, Efstathios (2015), "Understanding Modern Banking Ledgers Through Blockchain Technologies: Future of Transaction Processing and Smart Contracts on the Internet Money”, Banking Beyond Banks and Money, Springer, Cham., ss. 239-278.

Schermelleh-Engel, Karin - Mossbrugger, Helfried - Müller, Hans (2003), "Evaluating The Fit of Structural Equation Models: Test of Significance and Descriptive Goodness-ofFit Measures”, Methods of Psychological Research Online, 8(2), ss. 23-74.

Şuekinci, Cafer - Çatıkkaş, Özgür (2020), "Blok Zinciri Teknolojisinin Muhasebe ve Vergilendirme Üzerine Etkileri”, Mali Çözüm Dergisi, 30(162), ss. 51-65.

Uçma Uysal, Tuğba - Kurt, Ganite (2018), "Muhasebede ve Denetimde Blok Zinciri Teknolojisi”, Süleyman Demirel Üniversitesi İktisadi ve İdari Bilimler Fakültesi Dergisi, 23(2), ss. 467-481.

Walsh, Clara - O’Reilly, Philip - Gleasure , Rob - McAvoy, John - O’Leary, Kevin (2020), “Understanding Manager Resistance to Blockchain Systems”, European Management Journal.

Vijai, C. - Elayaraja, M. - Suriyalakshmi, S.M. - Joyce, D. (2019), “The Blockchain Technology and Modern Ledgers Through Blockchain Accounting”, Adalya Journal, 8(12), ss. 545-557.

(https://www.openepi.com/SampleSize/SSPropor.htm, (Erişim Tarihi: 24.02.2021). 